\title{
Comparison of postoperative quality of life for patients who undergo atrial myxoma excision with robotically assisted versus conventional surgery
}

\author{
Ming Yang, MD, Minghui Yao, PhD, Gang Wang, MD, Cangsong Xiao, MD, Yang Wu, MD, \\ Huajun Zhang, MD, and Changqing Gao, MD
}

\begin{abstract}
Background: Robotically assisted cardiac surgery is an alternative to conventional, open-chest surgery. Although studies have been done on the clinical effect, morbidity, and mortality of robotically assisted atrial myxoma excision, few have addressed surgical outcomes, such as pain, quality of life (QOL), and length of sick leave from work. In this study, our aim was to evaluate these clinical variables among patients after they undergo robotically assisted atrial myxoma excision surgery.
\end{abstract}

Methods: Between January 2007 and January 2013, a total of 93 patients underwent either conventional sternotomy or robotically assisted atrial myxoma excision in our unit. The 36-item Medical Outcomes Study Short Form Survey was used to assess the clinical outcomes in these patients postoperatively, at day 30 and 6 months.

Results: The QOL scores for 7 of 8 variables in the robotically assisted group were significantly higher than those in the conventional group at postoperative day $30(P<.05)$. The degree of pain and its influence on work or life was lower in the robotically assisted group $(P<.05)$, and these patients returned to work after $0.9 \pm 0.1$ months, whereas those in the conventional group needed a sick leave of $3.3 \pm 0.4$ months.

Conclusions: The level of restoration of normal QOL within 30 days after atrial myxoma surgery is excellent with the robotically assisted approach, which may enable early return to employment and satisfactory recovery. (J Thorac Cardiovasc Surg 2015;150:152-7)

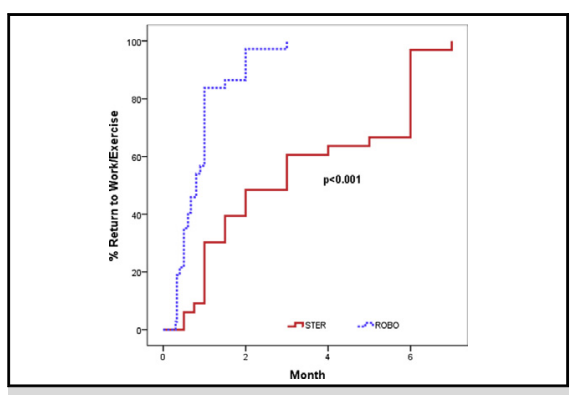

ROBO group returned to work, exercise, and normal life much earlier.

Central Message

Patient's QOL postoperatively is excellent by using robotic approach, which may enable an early return to employment and satisfactory recovery.

\section{Perspective}

Thanks to the development of minimally invasive technology such as robotic surgery, which not only proved to be safe and feasible but also enabled patients to recover as soon as possible, the patient has an alternative choice for their diseases.

See Editorial Commentary page 157.
Since the first successful removal of a left atrial myxoma using cardiopulmonary bypass, ${ }^{1}$ in 1954 , median sternotomy has become the most frequently used surgical approach for resection of cardiac masses, and has had excellent clinical outcomes. Over the past decade, robotically assisted cardiac surgery has been a rapidly evolving technology. In 2005, Murphy and colleagues ${ }^{2}$ performed the first successful removals of a left atrial myxoma, for 3 patients, by using a da Vinci Surgical System (Intuitive Surgical, Inc, Mountain View, Calif). The rapid recovery and excellent

\footnotetext{
From the Department of Cardiovascular Surgery, Chinese People's Liberation Army General Hospital, Beijing, People's Republic of China.

Ming Yang and Minghui Yao contributed equally to this article.

Received for publication Nov 20, 2014; revisions received Jan 14, 2015; accepted for publication Jan 29, 2015; available ahead of print March 11, 2015

Address for reprints: Changqing Gao, MD, Department of Cardiovascular Surgery, The People's Liberation Army General Hospital, No. 28, Fuxing Rd, Haidian District, Beijing, People's Republic of China 100853 (E-mail: gaochq301@ gmail.com)

$0022-5223 / \$ 36.00$

Copyright (C) 2015 by The American Association for Thoracic Surgery

http://dx.doi.org/10.1016/j.jtcvs.2015.01.056
}

cosmesis indicated that robotically assisted excision of atrial myxomas was feasible and deserved further clinical evaluation.

In 2010, we reported that the resection of an atrial myxoma using robotics technology was efficacious and had good short-term follow-up results. ${ }^{3}$ In 2012, Schilling and colleagues ${ }^{4}$ similarly reported that robotically assisted excision of atrial myxomas was safe and might be an alternative to traditional open surgery. These reports focused mainly on survival rate, the incidence of cardiac events, reducing incision size, and surgical safety and feasibility. However, subjective outcome measures, such as patients' pain level and quality of life (QOL) after robotically assisted atrial myxoma excision, were not evaluated.

Outcome measures examine an individual's ability to perform various activities of daily life, as a means of evaluating operation success; such measures assess physical rehabilitation, mental rehabilitation, exercise capacity, and return to employment. Morgan and colleagues ${ }^{5}$ previously 


\section{Abbreviations and Acronyms \\ $\mathrm{QOL}=$ quality of life \\ SF-36 $=$ Medical Outcomes Study Short Form Survey (36 items)}

evaluated QOL using the Medical Outcomes Study Short Form Survey (SF-36) for patients who underwent robotically assisted atrial septal defect repair. They concluded that the robotics technology could improve QOL on postoperative day 30. However, the literature on assessment of QOL after robotically assisted myxoma resection was limited. Therefore, the aim of our study was to evaluate postoperative QOL by comparing robotically assisted versus conventional surgical approaches, using a controlled clinical trial.

\section{METHODS}

\section{Patient Selection}

A total of 93 cases of surgery for atrial-mass excision, performed in our department between January 2007 and January 2013, were selected for this study. Among these cases, 49 patients were treated with use of the da Vinci Surgical System (robotically assisted group), including 45 patients who had a left atrial myxoma, and 4 who had a right atrial myxoma. A total of 44 patients underwent conventional median sternotomy (conventional group), including 39 patients with a left atrial myxoma, and 5 patients with a right atrial myxoma.

\section{Quality-of-Life Assessment}

Patients' QOL postoperatively at day 30 and 6 months was assessed by retrospectively administering a questionnaire, including: (1) the SF-36 (a set of 36 questions, used to score 8 dimensions of health status, including bodily pain, vitality, mental health, general health, physical functioning, role limitations due to physical problems, role limitations due to emotional problems, and social functioning); and (2) 3 supplementary questions on severity of pain, the adverse effect of physical pain on daily life, and the length of their sick leave from work, as described elsewhere. ${ }^{6}$ The questionnaire was delivered to patients with instructions on how to complete the survey. Forty-six patients $(93.9 \%)$ in the robotically assisted group, and 38 patients $(86.4 \%)$ in the conventional group successfully completed the surveys and returned the quality of life on SF36 questionnaires. The study was approved by the institutional review board.

\section{Robotically Assisted Operative Technique}

All patients received general anesthesia and were intubated for single-lung ventilation. A transesophageal echocardiography probe and an arterial pressure monitoring line were inserted. The cardiopulmonary bypass was established via right internal jugular venous cannulation, and right femoral arterial and venous cannulation.

A myxoma of the right atrium was excised through a right atriotomy on the beating heart. For the myxoma of the left atrium, the ascending aorta was crossclamped with a Chitwood crossclamp (Scanlon International, Minneapolis, Minn), and the heart was arrested before the mass was removed. The atriotomy was closed with 4-0 polytetrafluoroethylene (GoreTex; Zymed Laboratories, San Francisco, Calif) sutures in a running fashion. After the crossclamp was released, and the heart was meticulously de-aired, the patient was weaned from the cardiopulmonary bypass, and chest drains were placed. The integrity of the septum and complete excision of the atrial mass were confirmed by transesophageal echocardiography assessment.

\section{Statistical Analysis}

All categoric data were presented in percentages and were compared in the means of $\chi^{2}$ analysis. Continuous data were described as mean \pm SD. Normally distributed data sets were compared by using independent $t$ tests. The statistical analyses were performed with SPSS, version 17 (SPSS, Inc, Chicago, Ill).

\section{RESULTS}

\section{Patient Demographics}

Table 1 outlines clinical demographics of the robotically assisted and conventional sternotomy groups. The mean age and the gender ratio were similar $(P$ not significant $)$ in the 2 groups. The prevalences of various comorbidities, including diabetes mellitus, hypertension, chronic obstructive pulmonary disease, chronic renal failure, and preoperative atrial fibrillation were similar in the 2 groups as well ( $P$ not significant). The size of the atrial myxoma was similar in the 2 groups ( $P$ not significant; range [robotically assisted] $1.5 \mathrm{~cm} \times 2.0 \mathrm{~cm}$ to $5.0 \mathrm{~cm} \times 7.0 \mathrm{~cm}$ vs [conventional] $1.8 \mathrm{~cm} \times 2.0 \mathrm{~cm}$ to $5.0 \mathrm{~cm} \times 6.0 \mathrm{~cm}$ ).

\section{Operative Outcome}

All operations were performed successfully, and pathologic diagnosis was confirmed in all cases.

TABLE 1. Baseline characteristics of the robotically assisted versus conventional sternotomy groups

\begin{tabular}{|c|c|c|c|c|}
\hline Variable & Robotically assisted surgery $(n=49)$ & Conventional sternotomy $(n=44)$ & $t\left(x^{2}\right)$ & $P$ value \\
\hline Age $(y ;$ mean $\pm S D)$ & $47.7 \pm 13.0$ & $51.2 \pm 12.1$ & 1.23 & .57 \\
\hline Gender & & & 0.61 & .53 \\
\hline Male (n) & 24 & 18 & & \\
\hline Female (n) & 25 & 26 & & \\
\hline Body mass index $\left(\mathrm{kg} / \mathrm{m}^{2} ;\right.$ mean $\left.\pm \mathrm{SD}\right)$ & $23.2 \pm 3.6$ & $23.5 \pm 3.8$ & 0.34 & .66 \\
\hline \multicolumn{5}{|l|}{ Comorbidities } \\
\hline Diabetes mellitus & $5(10.2)$ & $7(15.9)$ & 0.67 & .54 \\
\hline Hypertensive disease & $8(16.3)$ & $11(25)$ & 1.07 & .32 \\
\hline Arterial embolism & $4(8.2)$ & $4(9.1)$ & 0.00 & .87 \\
\hline Preoperative atrial fibrillation & $1(2.0)$ & $1(2.3)$ & 0.45 & .63 \\
\hline Myxoma size $(\mathrm{cm} \times \mathrm{cm})$ & $2.6 \times 4.8$ & $3.1 \times 4.3$ & 0.15 & .28 \\
\hline
\end{tabular}

Data are expressed as n (\%), unless otherwise indicated. SD, Standard deviation. 
TABLE 2. Operative outcomes of 2 groups

\begin{tabular}{|c|c|c|c|c|}
\hline Variable & Robotically assisted surgery $(n=49)$ & Conventional sternotomy $(n=44)$ & $\mathbf{t}\left(\mathbf{x}^{2}\right)$ & $P$ value \\
\hline Myxoma location & & & 0.03 & .73 \\
\hline Left atrium (n) & 45 & 39 & & \\
\hline Right atrium (n) & 4 & 5 & & \\
\hline CPB time (min) & $79.7 \pm 16.5$ & $68.6 \pm 27.8$ & 3.6 & .03 \\
\hline Crossclamp time (min) & $44.8 \pm 18.3$ & $39.3 \pm 19.7$ & 0.17 & .30 \\
\hline Ventilation time $(\mathrm{h})$ & $7.1 \pm 2.1$ & $8.4 \pm 3.0$ & 4.42 & .00 \\
\hline ICU length of stay (d) & $2.7 \pm 1.0$ & $4.1 \pm 3.6$ & 2.23 & .04 \\
\hline Postoperative hospital length of stay (d) & $6.2 \pm 1.3$ & $8.7 \pm 1.9$ & 3.76 & .04 \\
\hline Atrial fibrillation (n [\%]) & $2(4.1)$ & $8(18.2)$ & 3.44 & .04 \\
\hline
\end{tabular}

Values are mean $\pm \mathrm{SD}$, unless otherwise indicated. $C P B$, Cardiopulmonary bypass; $I C U$, intensive care unit.

Cardiopulmonary bypass time was $79.7 \pm 16.5$ minutes for the robotically assisted group, and $68.6 \pm 27.8$ minutes for the conventional group $(P=.03)$; and aorta crossclamping time was $44.8 \pm 18.3$ minutes and $39.3 \pm 19.7$ minutes, respectively $(P>.05)$. The postoperative ventilation time and the intensive care unit stay of the robotically assisted group were shorter than those for the conventional group $(P<.05)$ (Table 2$)$.

\section{Postoperative Complications}

No operative mortality or major complication, such as stroke, renal failure, excessive bleeding, reoperation, or embolism was observed in any patient within 30 days of surgery. The patients in the robotically assisted group had a significantly lower rate of atrial fibrillation after surgery $(4.1 \%[\mathrm{n}=2]$ vs $18.2 \%[\mathrm{n}=8] ; P<.05$; Table 2$)$.

\section{Assessment of QOL With SF-36}

Compared with the conventional group, the patients in the robotically assisted group demonstrated significantly improved scores postoperatively in 7 categories $(P<.05)$ within 30 days after surgery, including physical functioning, role limitations due to physical problems, bodily pain, general health, vitality, social functioning, and limitations due to emotional problems. The general health of patients who had robotically assisted myxoma excision surgery was still significantly different, compared with that of patients who underwent conventional sternotomy $(P=.03)$ (Tables 3 and 4; Figures 1 and 2).

\section{Three Supplementary QOL Questions}

The patients in the robotically assisted group had less pain at day 30 after surgery, and approximately $95.7 \%$ $(\mathrm{n}=44)$ experienced no pain to mild pain. A total of $47.3 \%(\mathrm{n}=44)$ in the conventional group, and $4.3 \%$ $(\mathrm{n}=2)$ in the robotically assisted group experienced moderate-to-severe pain, versus $52.7 \%(\mathrm{n}=20)$ in the conventional group $(P<.01)$. The patients in the robotically assisted group experienced less of an adverse effect from physical pain on daily life and work: $63.2 \%(n=24)$ had no effect to a mild effect, versus $36.8 \%(n=14)$ in the conventional group (Table 5). The mean time to return to work or daily life was $0.9 \pm 0.1$ months in the robotically assisted group, and $3.3 \pm 0.4$ months in the conventional group $(P<.01$; Figure 3$)$.

\section{DISCUSSION}

Minimally invasive approaches are being applied with increasing frequency in all areas of cardiac surgery, including mitral valve repair, coronary artery bypass grafting surgery, atrial septal defect repair, and myxoma excision. ${ }^{8-10}$ Furthermore, robotically assisted techniques for both percutaneous coronary intervention and abdominal aortic endovascular surgery have been developed. The basic feasibility and safety of approaches

TABLE 3. Comparison between the robotically assisted versus conventional sternotomy groups, of SF-36 results at postoperative day 30

\begin{tabular}{|c|c|c|c|c|}
\hline Variable & Robotically assisted surgery $(n=49)$ & Conventional sternotomy $(n=44)$ & $t\left(x^{2}\right)$ & $P$ value \\
\hline Bodily pain & $82.6 \pm 11.9$ & $73.2 \pm 17.7$ & 2.65 & .00 \\
\hline General health & $78.0 \pm 7.6$ & $61.9 \pm 13.6$ & 6.76 & .02 \\
\hline Mental health & $82.7 \pm 9.3$ & $73.6 \pm 8.3$ & 9.44 & .90 \\
\hline Physical functioning & $89.7 \pm 6.3$ & $75.3 \pm 11.0$ & 6.12 & .00 \\
\hline Role, physical* & $77.7 \pm 14.2$ & $53.0 \pm 13.6$ & 7.40 & .00 \\
\hline Role, emotional $\uparrow$ & $77.8 \pm 16.0$ & $46.7 \pm 20.7$ & 6.71 & .03 \\
\hline Social functioning & $74.3 \pm 15.6$ & $42.3 \pm 20.7$ & 7.34 & .03 \\
\hline Vitality & $78.8 \pm 10.4$ & $60.3 \pm 7.4$ & 7.87 & .04 \\
\hline
\end{tabular}

Values are mean $\pm \mathrm{SD}$, unless otherwise indicated. *Role limitations due to physical health problems. †Role limitations due to emotional health problems. 
TABLE 4. Comparison between the robotically assisted versus conventional sternotomy groups, of SF-36 results at 6 months after surgery

\begin{tabular}{|c|c|c|c|c|}
\hline Variable & Robotically assisted surgery $(n=49)$ & Conventional sternotomy $(n=44)$ & $t\left(x^{2}\right)$ & $P$ value \\
\hline Bodily pain & $98.8 \pm 3.2$ & $98.0 \pm 4.3$ & 2.08 & .11 \\
\hline General health & $94.3 \pm 10.6$ & $88.8 \pm 12.1$ & 2.04 & .03 \\
\hline Mental health & $95.4 \pm 7.4$ & $88.6 \pm 7.0$ & 3.92 & .60 \\
\hline Physical functioning & $98.0 \pm 2.8$ & $94.7 \pm 6.2$ & 2.91 & .08 \\
\hline Role, physical* & $99.8 \pm 1.31$ & $100 \pm 0.0$ & 0.93 & .06 \\
\hline Role, emotional $\uparrow$ & $100 \pm 0.0$ & $100 \pm 0.0$ & - & - \\
\hline Social functioning & $99.7 \pm 1.32$ & $99.2 \pm 3.1$ & 0.93 & .06 \\
\hline Vitality & $94.2 \pm 7.8$ & $83.1 \pm 9.5$ & 5.33 & .43 \\
\hline
\end{tabular}

Values are mean $\pm \mathrm{SD}$, unless otherwise indicated. *Role limitations due to physical health problems. $\dagger$ Role limitations due to emotional health problems.

involving robotics technology in cardiovascular medicine have been demonstrated. ${ }^{11}$

Excision of cardiac tumors has been particularly amenable to minimally invasive approaches. The da Vinci Surgical System provides assistance to surgeons via telemanipulation through a master-controller activation principle with a 3-dimensional intracardiac camera. Surgical telemanipulation seems to be an ideal method for operating accurately through small incisions and in restricted spaces. Chitwood ${ }^{12}$ showed that endoscopic left atrial myxoma surgery could be performed safely and with "gold standard" results. In fact, robotics technology can potentially provide not only many benefits, including reduced bleeding and transfusion of blood products, but also improved patient satisfaction, subtler cosmetic changes, and shorter hospital stays. ${ }^{3,13,14}$

However, our study showed that cardiopulmonary bypass time, as well as aortic crossclamp time, for the robotically assisted surgery was longer than that with conventional sternotomy. But the results were not associated with

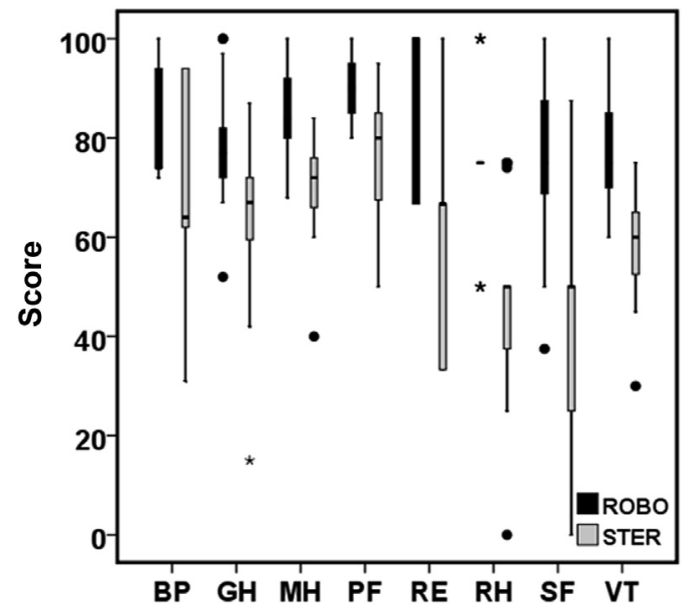

FIGURE 1. Results of the SF-36 for the ROBO (black bars) and STER (gray bars) groups at postoperative day 30. ROBO, Patient group that underwent robotically assisted surgery; STER, patient group that underwent conventional sternotomy; $B P$, bodily pain; $G H$, general health; $M H$, mental health; $P F$, physical functioning; $R E$, role limitations due to emotional health problems; $R H$, role limitations due to physical health problems; $S F$, social functioning; $V T$, vitality. prolonged early postoperative outcomes in the robotically assisted group in terms of mechanical ventilation time, intensive care unit length of stay, or total hospital length of stay. These reductions in the length of stay are most likely due to the enhanced recovery noted with minimally invasive surgery, ${ }^{15}$ likely owing to patients experiencing less surgical trauma and less pain, leading to a faster return to normal activity.

Although prior studies have demonstrated satisfactory patient acceptance of robotically assisted surgery, whether the perceived advantages translate into improved QOL after robotically assisted atrial myxoma excision is unclear. We therefore sought to understand the early postoperative functional effect of surgical myxoma excision using a standard, validated QOL assessment tool. As a measure of general health status, the SF-36 has been reported to be valid and reliable in evaluating the impact of changes in symptoms after coronary artery bypass grafting and mitral valve repair, and in normal populations. ${ }^{16,17}$ Thus, the survey seems to be a suitable instrument to evaluate

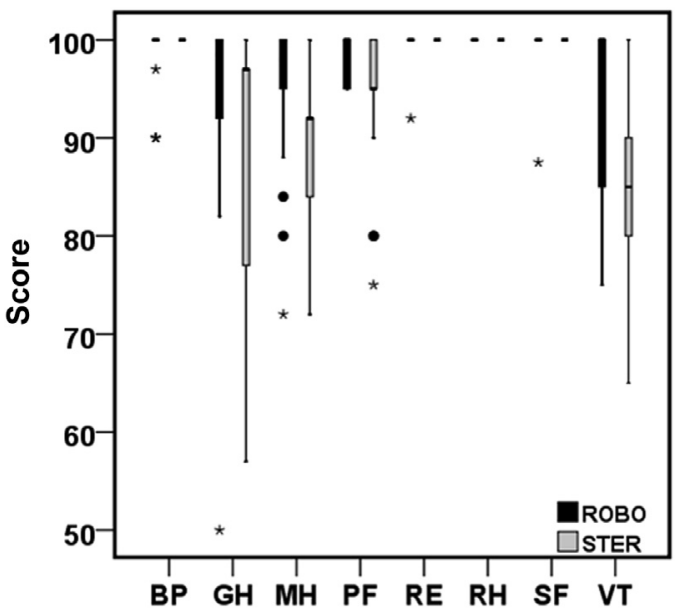

FIGURE 2. Results of the SF-36 for the ROBO (black bars) and STER (gray bars) groups at 6 months after surgery. ROBO, Patient group that underwent robotically assisted surgery; STER, patient group that underwent conventional sternotomy; $B P$, bodily pain; $G H$, general health; $M H$, mental health; $P F$, physical functioning; $R E$, role limitations due to emotional health problems; $R H$, role limitations due to physical health problems; $S F$, social functioning; $V T$, vitality. 
TABLE 5. Scale of pain and its adverse effect on work and daily life at day 30 after surgery, in the robotically assisted versus conventional sternotomy groups

\begin{tabular}{lcc}
\hline \multicolumn{1}{c}{ Variable } & $\begin{array}{c}\text { Robotically } \\
\text { assisted }(\mathbf{n}=\mathbf{4 9})\end{array}$ & $\begin{array}{c}\text { Conventional } \\
\text { sternotomy }(\mathbf{n}=\mathbf{4 4})\end{array}$ \\
\hline Severity of pain & & \\
None & $20(43.5)$ & $3(7.9)$ \\
Mild & $24(52.2)$ & $15(39.4)$ \\
Moderate & $2(4.3)$ & $18(47.4)$ \\
Severe & 0 & $2(5.3)$ \\
Adverse effect & & \\
None & $18(39.1)$ & $5(13.2)$ \\
Mild & $28(60.9)$ & $19(50)$ \\
Moderate & 0 & $12(31.6)$ \\
Severe & 0 & $2(5.3)$ \\
\hline Values are $\mathrm{n}(\%) \mathrm{t}\left(\mathrm{x}^{2}\right)=26.75$ for both groups. Differences were not significant.
\end{tabular}

Values are $\mathrm{n}(\%) . \mathrm{t}\left(\mathrm{x}^{2}\right)=26.75$ for both groups. Differences were not significant.

changes in health status after patients undergo surgery with one or the other of the 2 approaches, and to identify the main determinants of these changes.

Considering the data mentioned here, in our experience, postoperative physical status and mental health are the main concern for patients scheduled for a heart operation. Two explanations are possible for the outcome advantages of robotically assisted surgery. First, the robotics approach obviated the need for median sternotomy and reduced bodily pain and anxiety, thereby improving the scores for bodily pain, physical functioning, and role limitations due to emotional problems.

Although the sternotomy patients had a significantly higher rate of atrial fibrillation after surgery, they usually had a restored sinus rhythm before they were discharged. However, to determine whether the temporary resolution

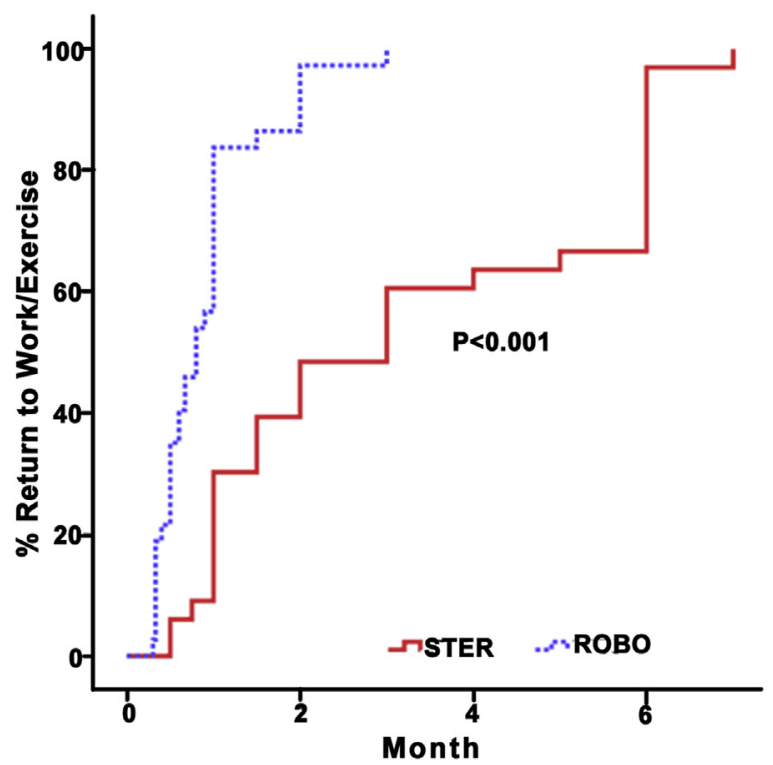

FIGURE 3. Kaplan-Meier analysis of the speed of the STER (solid red line) versus ROBO (dotted blue line) group returning to work or exercise. STER, Patient group that underwent conventional sternotomy; $R O B O$, patient group that underwent robotically assisted surgery. led to permanent resolution in these patients requires further study of these procedures, and collection of much more data on patients who had atrial fibrillation when they were discharged. Second, at our institution, we have observed that patients in the robotically assisted group were more satisfied with the aesthetic appearance of their surgical incisions, and the markedly improved cosmetic result enabled them to restore their social functioning, vitality, and general health faster, achieving higher scores, earlier, compared with their counterparts who underwent conventional sternotomy.

Few studies have examined postoperative QOL related to pain, and the length of time patients need to return to work after minimally invasive cardiac surgery, compared with conventional surgery via sternotomy. Compared with conventional sternotomy, totally thoracoscopic atrial septal defect closure without robotics technology assistance was associated with a faster recovery of physical functioning and better QOL. ${ }^{18}$ Suri $^{19}$ found that robotically assisted mitral valve repair was associated with slightly improved early QOL and return to employment-based activities, compared with a conventional approach. Our data indicate that the robotically assisted myxoma excision led to a higher QOL and a significantly shorter length of stay and time to return to work, compared with the conventional sternotomy. As the patients in the robotically assisted group perceived less pain, experienced a lower rate of postoperative complications, and achieved a normal life standard faster, they were able to go back to work sooner.

This study used multiple validated methods to evaluate the postoperative QOL in patients undergoing robotically assisted myxoma excision and compared their results with those of a cohort who underwent conventional surgery. Yet, our study has limitations. First, the 2 groups of patients were not randomized. In our institution, patients often seek a specific surgical approach; thus, the patients who chose to undergo a "new" procedure, such as robotically assisted surgery, could have been more likely to report positive postoperative experiences.

Second, the preoperative QOL data were not investigated. An imbalance between groups in preoperative QOL could have contributed to the difference in postoperative QOL. However, we believe that surgery has the strongest impact on patients' QOL during the first postoperative 6 months. Other unmeasured factors, such as family and financial status, young patients looking forward to the cosmetic result, and high-intensity exercise, could be underlying causes for the observed differences in preoperative outcomes.

In conclusion, this study showed that robotic excision of atrial myxoma was associated with shorter ventilation time, intensive care time, and postoperative hospital length of stay, and a lower incidence of postoperative atrial fibrillation. In addition, patients' QOL was improved after robotically assisted myxoma resection, compared with a conventional surgical approach. 


\section{Conflict of Interest Statement}

Authors have nothing to disclose with regard to commercial support.

\section{References}

1. Chitwood WR Jr. Clarence Crafoord and the first successful resection of a cardiac myxoma. Ann Thorac Surg. 1992;54:997-8.

2. Murphy DA, Miller JS, Langford DA. Robot-assisted endoscopic excision of left atrial myxomas. J Thorac Cardiovasc Surg. 2005;130:596-7.

3. Gao C, Yang M, Wang G, Wang J, Xiao C, Wu Y, et al. Excision of atrial myxoma using robotic technology. J Thorac Cardiovasc Surg. 2010;139:1282-5.

4. Schilling J, Engel AM, Hassan M, Smith JM. Robotic excision of atrial myxoma. J Card Surg. 2012;27:423-6.

5. Morgan JA, Peacock JC, Kohmoto T. Robotic techniques improve quality of life in patients undergoing atrial septal defect repair. Ann Thorac Surg. 2004;77: 1328-33.

6. Guirado VM, Taricco MA, Nobre MR, Couto EB Jr, Ribas ES, Meluzzi A, et al. Quality of life in adult intradural primary spinal tumors: 36-Item Short Form Health Survey correlation with McCormick and Aminoff-Logue scales. J Neurosurg Spine. 2013;19:721-35.

7. Gao C, Yang M, Wang G, Wang J. Totally robotic resection of myxoma and atrial septal defect repair. Interact Cardiovasc Thorac Surg. 2008:7:947-50.

8. Raju V, Burkhart HM, Cetta F Jr, Suri RM. Successful robot-assisted repair of congenital mitral valve regurgitation. Ann Thorac Surg. 2014;98:1085-7.

9. Halkos ME, Liberman HA, Devireddy C, Walker P, Finn AV, Jaber W, et al. Early clinical and angiographic outcomes after robotic-assisted coronary artery bypass surgery. J Thorac Cardiovasc Surg. 2014;147:179-85.
10. Xiao C, Gao C, Yang M. Totally robotic atrial septal defect closure: 7-year singleinstitution experience and follow-up. Interact Cardiovasc Thorac Surg. 2014;19: 933-7.

11. Bonatti J, Vetrovec G, Riga C, Wazni O, Stadler P. Robotic technology in cardiovascular medicine. Nat Rev Cardiol. 2014;11:266-75.

12. Chitwood WR. Current status of endoscopic and robotic mitral valve surgery. Ann Thorac Surg. 2005;79:s2248-53.

13. Modi P, Hassan A, Chitwood WR. Minimally invasive mitral valve surgery: a systematic review and meta-analysis. Eur J Cardiothorac Surg. 2008;34:943-52.

14. Gao C, Yang M, Wu Y, Wang G, Xiao C, Zhao Y, et al. Early and midterm results of totally endoscopic coronary artery bypass grafting on the beating heart J Thorac Cardiovasc Surg. 2011;142:843-9.

15. Pineda AM, Santana O, Zamora C, Benjo AM, Lamas GA, Lamelas J. Outcomes of a minimally invasive approach compared with median sternotomy for the excision of benign cardiac masses. Ann Thorac Surg. 2011;91:1440-4.

16. Bonaros N, Schachner T, Wiedemann D. Quality of life improvement after robotically assisted coronary artery bypass grafting. Cardiology. 2009;114:59-66.

17. Gjeilo KH, Wahba A, Klepstad P, Lydersen S, Stenseth R. Survival and quality of life in an elderly cardiac surgery population: 5-year follow-up. Eur $J$ Cardiothorac Surg. 2013;44:e182-8.

18. Ma ZS, Yin QY, Dong MF, Feng ZY, Wang LX. Quality of life in patients undergoing totally thoracoscopic closure for atrial septal defect. Ann Thorac Surg. 2011;92:2230-4.

19. Suri RM, Antiel RM, Burkhart HM. Quality of life after early mitral valve repai using conventional and robotic approaches. Ann Thorac Surg. 2012;93:761-9.

Key Words: robotic surgery, minimally invasive cardiac surgery, myxoma, quality of life

\section{EDITORIAL COMMENTARY}

\section{The life in your years}

Richard Lee, MD, MBA

See related article on pages 152-7.

The important thing to you is not the years in your life, but how much life in your years!

—Edward J. Stieglitz, MD, 1947

In this issue of the Journal, Yang and colleagues ${ }^{1}$ explore differences in "life in years" in "Comparison of

$\overline{\text { From the Center }}$ for Comprehensive Cardiovascular Care, St Louis University, St Louis, Mo.

Disclosures: Author has nothing to disclose with regard to commercial support.

Received for publication Feb 6, 2015; accepted for publication Feb 7, 2015; available ahead of print March 17, 2015.

Address for reprints: Richard Lee, MD, MBA, Center for Comprehensive Cardiovascular Care, Saint Louis University, 3635 Vista Ave, Desloge Towers 13th Floor, St Louis, MO 63110 (E-mail: rlee@slu.edu).

J Thorac Cardiovasc Surg 2015;150:157-8

$0022-5223 / \$ 36.00$

Copyright (c) 2015 by The American Association for Thoracic Surgery

http://dx.doi.org/10.1016/j.jtcvs.2015.02.021
Postoperative Quality of Life Between Patients With Robotic and Conventional Atrial Myxoma Excision." At a single center, they compared 44 patients undergoing conventional sternotomy for atrial myxoma excision with 49 patients in whom the myxoma was removed robotically. The SF-36 and several supplementary questions,

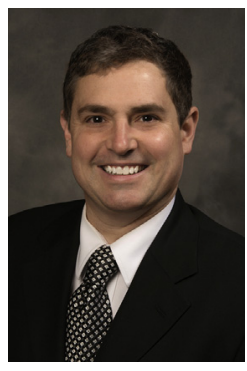
including pain and mean return to work, were analyzed.

At 30 days, nearly every metric in the SF- 36 was better in the robotic group. Although the gap narrowed in the course of 6 months, there were still several areas that trended toward improved outcomes in the robotic group. The robotic group had less pain, less adverse effect, and a much quicker return to work.

The good news for a surgeon who only uses a conventional approach is that it is safe and that, at 6 months at least, there is not much advantage to a less invasive approach. The 